\title{
Percepciones de satisfacción, apropiación y mantenimiento de los conjuntos habitacionales del Estado: el caso de la Villa General Bernales de la comuna de Puente Alto
}

\author{
Perceptions of satisfaction, appropriation and maintenance of housing complexes of the State: The case of the Villa
}

General Bernales in Puente Alto district

\section{Andrés Godoy Ossandon*}

Recibido: 18 de diciembre de 2018

Aceptado: 26 de abril de 2019

\section{Resumen}

La política de vivienda social en Chile, durante décadas ha contado con usuarios con percepciones de satisfacción y apropiación barrial negativas, sumado a barrios que en su componente físico se han deteriorado con el paso de los años. Esta situación ha traído diferentes modificaciones a la política habitacional a partir del año 2001. De este contexto, el objetivo general de la presente investigación fue conocer en un caso de la actual política habitacional, las percepciones de satisfacción y formas de apropiación barrial con la que cuentan los usuarios, junto con analizar el estado físico del barrio construido. Lo anterior, es visto mediante el estudio de caso del comité y posterior conjunto habitacional Villa General Bernales, provenientes del campamento Peñoncito de la comuna de Puente Alto, quienes se trasladan a su nuevo barrio en febrero del 2016. El estudio se llevó a cabo a través de métodos cualitativos, donde se realizó un proceso de observación participante y ocho entrevistas en profundidad. Algunos de los principales resultados, dan cuenta de alto grado de satisfacción y apropiación barrial por parte de los vecinos, y de un barrio que se ha mantenido en el tiempo.

Palabras clave: apropiación barrial, mantención de conjuntos, participación, política habitacional, satisfacción.

\begin{abstract}
The social housing policy in Chile, for decades has had users with negative neighborhood satisfaction and appropriation perceptions, added to neighborhoods that in their physical component have deteriorated over the years. This situation has brought different modifications to the housing policy since 2001. In this context, the aim was to explore the perceptions of satisfaction and forms of appropriation of users in their neighborhoods, by using a case of the current housing policy, and also to analyze the physical situation of the built environment. The case study is a previous local committee and currently a housing area called Villa General Bernales, whith people who lived in the Peñoncito slum in the Puente Alto district, and they moved to this new neighborhood in February 2016. The methodology includes qualitative methods, where a process of participant observation and a series of in-depth interviews were carried out. Some of the main results show a high level of satisfaction and neighborhood appropriation from the neighbors, and a neighborhood that has been maintained over time.
\end{abstract}

Keywords: appropriation, housing policy participation, , satisfaction, maintenance.

\footnotetext{
* Filiación: Universidad Alberto Hurtado, Santiago, Chile. Contacto: godoy.ossandon91@gmail.com
}

Cómo citar: Godoy, A. (2019). Percepciones de satisfacción, apropiación y mantenimiento físico de los conjuntos habitacionales del Estado: el caso de la Villa General Bernales de la comuna de Puente Alto. Revista de Urbanismo, 40, 1-13. https://doi.org/10.5354/0717-5051.2018.51938 


\section{Introducción}

La política habitacional y la producción de viviendas sociales aplicadas por el Estado Chileno ha ido variando en el tiempo en cuanto a su énfasis y características regulatorias. Lo anterior, ha tenido implicancias tanto en la calidad y características de la vivienda y los conjuntos habitacionales construidos, como en los niveles de satisfacción y apropiación barrial por parte de los beneficiarios de dichos conjuntos.

En este sentido, diferentes estudios como Rodríguez y Sugranyes (2004), Sabatini, Cáceres y Cerda (2001) e Hidalgo, Urbina, Alvarado y Paulsen (2017) muestran que el período que va desde la década de los ' 80 a los ' 90 , es un ciclo de la política habitacional en donde se han manifestado escasos niveles de satisfacción residencial y apropiación barrial por parte de los usuarios de los conjuntos construidos en dicho periodo.

Un ejemplo atingente a esta situación, es un estudio de caso realizado a algunos conjuntos habitacionales del sector de Bajos de Mena en la comuna de Puente Alto, por Hidalgo et al. (2017), en donde a partir de una escala de satisfacción, se muestra que, en su mayoría, los encuestados de conjuntos habitacionales construidos durante los años ' 90 , se declaran muy insatisfechos con la infraestructura y el tamaño de su vivienda, así como con el equipamiento y servicio urbano del barrio.

Por otro lado, en cuanto a su valoración por el barrio, se declaran muy insatisfechos con componentes como son la tranquilidad del sector o los niveles de delincuencia existentes en éste. A su vez, en términos de apropiación barrial, se declaran muy insatisfechos en cuanto al ambiente residencial.

Esta situación condice con que dichos conjuntos -más allá del amplio análisis que existe respecto a sus condiciones de diseño y requerimientos técnicos- son espacios físicos que se han visto deteriorados a través del paso del tiempo, por diferentes motivos, que tienen relación con necesidades materiales por parte de los vecinos, como por la mala utilización de espacios o por la escasa calidad del diseño arquitectónico.

Por ejemplo, según Rodríguez y Sugranyes (2004): "Las viviendas tienen todo tipo de ampliaciones informales...Los riesgos de terremoto, incendio o de multa municipal no frenan la necesidad urgente de más espacio. Estas ampliaciones son nuevas "callampas" que ocupan antejardines, pasajes y espacios comunes." (p. 56). Por otro lado, los autores evidencian problemas de coordinación entre los habitantes de los conjuntos: “Un sistema de condominio o propiedad horizontal que sus habitantes no logran entender, ya que nadie se lo ha explicado previamente. La convivencia entre los habitantes en estas viviendas y edificios hacinados es difícil” (p. 56).

Otro aspecto que habla del deterioro sufrido en estos espacios y de los niveles de inconformidad por parte de los vecinos, se refleja en los diferentes programas del Estado que han debido generarse para intervenir en procesos de regeneración física y social. Hidalgo et al. (2017) muestran que, durante el año 2006 en adelante, se han debido desarrollar tres programas del Ministerio de Vivienda que vayan dentro de esta línea de trabajo: el Programa de recuperación de condominios sociales, el Programa de Recuperación de Barrios y el Programa Quiero Mi Barrio.

De este modo, se evidencia la problemática urbana de la construcción de viviendas sociales de escasa calidad según los estudios, pero donde además consecuentemente los usuarios no cuentan con niveles de satisfacción y de apropiación barrial, y donde los barrios construidos se comienzan a deteriorar con el tiempo.

Para el periodo que va del año 2000 en adelante, el Estado busca dar respuesta a estas problemáticas, mediante la creación del programa Fondo Solidario de Vivienda regulado por el Decreto Supremo 174, modificado en el año 2011, por el Fondo Solidario de Elección de Vivienda regulado por el Decreto Supremo 49. Estos programas y sus respectivas modificaciones sientan las bases de la política habitacional actual, la cual atiende la situación de exclusión que viven los grupos más desfavorecidos del país.

Algunas de las condiciones más importantes que incorporan estos programas, que buscan mejorar los niveles de satisfacción residencial y apropiación barrial son:

- Promover postulación de tipo colectiva, que permita que grupos organizados en comités de vivienda, puedan de manera conjunta pasar a vivir en nuevos conjuntos habitacionales. Esto con la idea de que las 
familias puedan mantener sus redes e identidad grupal

- La creación de planes de acompañamiento social que permita que las familias cuenten con ayuda en términos de organización de la demanda, involucramiento en el desarrollo del proyecto, preparación para ser futuros propietarios, tareas de administración y copropiedad de los barrios.

- Aumentar el estándar técnico de los barrios y hogares, exigiéndose viviendas que cuenten con una mejor materialidad y espacialidad que sus antecesores, dejando además la posibilidad que los usuarios del programa puedan proyectar un crecimiento de sus viviendas según sus necesidades familiares, construyéndose viviendas con posibilidades de ampliación.

- Involucrar a las familias en el diseño de sus viviendas y barrios, cuando se trata de postulaciones colectivas. Por lo cual, por un lado, busca diagnosticar las necesidades de estos, con el fin de que los nuevos barrios respondan a sus características y requisitos. Como también una serie de talleres participativos en los cuales los usuarios puedan expresar su opinión y tomar decisiones en relación con el diseño de los conjuntos.

- Se implementa la constitución de las Entidades de Gestión Social (EGIS), quienes serán instituciones públicas o privadas, que funcionan como mediadores entre el Estado y las constructoras, siendo los encargados diseñar el proyecto, realiza el acompañamiento social y contratar a la constructora del proyecto.

En este escenario, la presente investigación tuvo como principal objetivo conocer en un caso de la actual política habitacional, las percepciones de satisfacción y formas de apropiación barrial con la que cuentan los usuarios, junto con analizar el estado físico del barrio construido. Siendo la pregunta de investigación:

¿Cuáles son las percepciones de satisfacción, apropiación barrial, y mantención física de conjuntos habitacionales, construidos bajo los lineamientos de la actual política habitacional?
Lo anterior visto en el caso de la Villa General Bernales de la comuna de Puente Alto, durante el segundo semestre del año 2016.

De esto se desprenden los siguientes objetivos específicos:

- Conocer percepciones de los habitantes estudiados, en cuanto a su vivienda, el barrio y las relaciones vecinales que se dan en su interior.

- Observar el comportamiento de los sujetos del estudio al interior de sus viviendas y barrio.

- Análisis visual de la mantención y cuidado del barrio en el tiempo

En esta línea, la hipótesis que guió la investigación fue que los usuarios de las actuales políticas habitacionales cuentan con percepciones positivas de satisfacción y apropiación de su barrio, lo cual impacta en que sea posible que la comunidad se encuentre mayormente cohesionada, y logre administrar y mantener el componente material de su barrio en el tiempo.

\section{Villa General Bernales}

El presente artículo se enmarca en la realización de un estudio de caso acerca de -familias beneficiarias de la actual política habitacional- pertenecientes al conjunto habitacional Villa General Bernales de la comuna de Puente Alto, en Santiago de Chile. Dichas familias son provenientes, en su mayoría, de un asentamiento irregular llamado "Peñoncito" ubicado en la misma comuna.

El campamento Peñoncito, se encontraba ubicado en la calle el Peñón, con la calle Camilo Henríquez. Y su nombre como es apreciable, es a partir de la calle donde se instaura el campamento. Este asentamiento irregular o campamento, se conforma a principios de la década de los noventa, en función de la necesidad de diferentes familias, no necesariamente relacionadas entre sí, por contar con un lugar donde poder habitar, debido a su situación de vulnerabilidad, la cual no les permite contar con los medios necesarios para adquirir una vivienda de forma regular, mediante el mercado inmobiliario. 
Así, como ocurre con la mayoría de los asentamientos irregulares en general, poco a poco comenzaron a llegar más personas con la necesidad de contar con una vivienda para estar junto a su núcleo familiar (al final del campamento vivían alrededor de 53 familias), generándose un espacio habitacional caracterizado por contar con viviendas de escasa materialidad (madera, lata, desechos y otros), sin áreas verdes o espacios de recreación y sin ningún tipo de servicio básico. Habitado además por familias con alta vulnerabilidad económica.

Para el año 2005, se consolidan estructuras de organización, mediante la constitución de un comité de vivienda y se elige una directiva de forma democrática, la cual busca representar los intereses y necesidades de todas las familias del lugar. De este modo, nace la idea de desarrollar el proyecto habitacional Villa General Bernales.

Para inicios del 2016, las familias del campamento Peñoncito, junto a familias de otros campamentos y allegados del sector, reciben las llaves de su vivienda definitiva, e inician su vida en la Villa General Bernales.

Las personas entrevistadas comentan haber participado de un proceso en el cual la comunidad fue un actor protagónico en el desarrollo del proyecto habitacional y concreción de su actual barrio. Cumpliendo a cabalidad con las exigencias normativas actuales, teniendo injerencia en decisiones tales como, la elección del terreno del conjunto, el diseño y distribución de este, 0 en las relaciones contractuales con la constructora mandatada para el desarrollo del mismo. Por otro lado, respecto a la conformación social del conjunto, el proceso también habría sido liderado desde una perspectiva participativa, siendo las propias familias quienes decidieron las personas que conformarían el condominio social, como a su vez, respecto a las normas y reglas que se exigirían al interior del conjunto.

\section{Marco teórico}

Edith Kuri (2013), considera que en general el espacio ha sido abordado como algo dado naturalmente, es decir, como mero escenario del quehacer humano. Sin embargo, la autora argumenta que el espacio es un proceso que es resultado de las relaciones sociales, las que, a su vez, son configuradas por el lugar donde se desarrollan.

Además, las prácticas en espacios o territorios se encuentran condicionados por las percepciones 0 significados que los sujetos le otorgan a lugar que habitan, lo cual es reforzado por Vidal y Pol (2005), quiénes mencionan otro elemento que es clave para esta investigación, el cual hace alusión con que:

El significado del espacio se deriva, en definitiva, de la experiencia que en éste se mantiene, lo que incluye el aspecto emocional como ha destacado José Antonio Corraliza (1987, 2000). La experiencia emocional en los lugares implica que las acciones que se desarrollan en el lugar y las concepciones que del lugar se generan están imbricadas. De esta premisa también parte Gustafson (2001a), en un estudio empírico, al plantear tres polos alrededor de los cuales emerge el significado: el self, los otros y el entorno. (Vidal y Pol, 2005, p. 295)

Este punto es considerado como relevante para la investigación, debido que da entender como las percepciones de los habitantes de un espacio (que en este caso son las de satisfacción y apropiación), se forman a partir de componentes experimentales $y$ emocionales y que, además, tendrían estrecha relación con el componente físico de un territorio que, en este caso sería, posible de relacionar con el deterioro o no deterioro del conjunto habitacional estudiado.

De este modo, se entenderá que las percepciones de satisfacción material de la vivienda y el barrio estarán conformadas a partir del significado que los entrevistados han construido por su vivienda y barrio, combinando expectativas, historia personal y grupal, condiciones materiales del barrio, junto con las prácticas grupales que se dan en el espacio público o al interior de las viviendas.

En cuanto al concepto de apropiación barrial fue trabajado a partir de la definición de arraigo trabajado en Marín, Link y Valenzuela (2017, p.135): “Quienes consideran al arraigo como un estado donde los individuos se anclan o sujetan emocionalmente a partir de un componente espacial, cultural o social". 
Es decir que, tal como indica Márquez (Marín, Link y Valenzuela, 2017) los procesos de apropiación del espacio tienen estrecha relación entre: "El sujeto y el lugar de residencia, otorgando un sentimiento de comunidad y redes de protección: “[...] en el ejercicio cotidiano de recorrer el barrio y saludar a los vecinos [el arraigo] se reactualiza una y otra vez" (p.135).

Por último, se considera que las actuales exigencias de las políticas habitacionales promueven ciertos procesos de participación ciudadana que podrían incidir en mejorar las percepciones de satisfacción y apropiación barrial.

Castillo Cubillos (2017) comenta que, en la actualidad, se entiende la participación ciudadana, como un eje prioritario para asegurar la gobernanza de las sociedades, elemento que ha sido fortalecido a partir de los '90. En esta línea, se apunta a la participación ciudadana como el "el mecanismo a través del cual los ciudadanos participan en la formulación y ejecución de las políticas públicas" (p. 174).

Además, según la autora, es posible definir diferentes modos de participación a partir del objetivo que tenga la iniciativa y de la metodología de trabajo que utilice para involucrar a la sociedad civil. Por lo cual habla de la existencia de 5 dispositivos o clasificaciones de participación. La participación-experiencia, en el cual "descansan en la idea de que nadie conoce mejor los problemas de un barrio que los vecinos que viven en él, de manera que dicho "saber de la experiencia" justifica y organiza las prácticas en el seno de los mismos" (Annunziata, 2013, p. 264).

En este sentido y, según las entrevistas recogidas, es posible definir a priori que el proceso experimentado por los vecinos de la Villa General Bernales se centró en un proceso en su mayoría (una intervención puede transitar por los diferentes tipos de participación) de participación-experiencia, en el cual se buscó fortalecer las necesidades y requerimientos de los vecinos, por ejemplo, en temáticas como la elección de la ubicación del terreno donde se desarrolló el proyecto habitacional.

\section{Metodología}

Dado el enfoque de la investigación y objetivos, se considera que las técnicas más pertinentes para comprender los niveles de satisfacción, apropiación barrial y mantención física del conjunto eran:

Observación participante. Se escoge esta técnica debido ya que se tiene por objetivo ver in situ las prácticas y uso del espacio común e individual que realizan los habitantes del barrio Villa General Bernales. De este modo se entiende mediante esta técnica posible interpretar las formas de apropiación barrial de los habitantes del conjunto.

Por otro lado, la observación participante permitió realizar un análisis visual del conjunto, que permite describir si este se ha deteriorado o no, en cuanto a su dimensión física desde que el conjunto fue recibido por sus habitantes.

La pauta de observación fue la siguiente:

- Observación del conjunto en cuanto a su dimensión física: mantención y cambios de las viviendas (cierre, fachadas, ampliaciones, etc). Mantención de espacios comunitarios. (cuidado, modificaciones).

- Interacciones entre vecinos.

- Prácticas en espacios comunitarios (usos incompatibles, usos ociosos, usos inciviles).

- Presencia de actividades comunitarias.

- Artefactos que utilizan los grupos observados.

- Hechos que sean considerados como relevantes.

Entrevista en profundidad. Fue utilizada debido que es una técnica de recolección de información que permite conocer por parte de los propios beneficiarios cuáles son sus percepciones de satisfacción residencial y apropiación barrial, junto con su parecer respecto al mantenimiento del conjunto. De este modo, la entrevista se desarrolla en base a tópicos relacionados, con satisfacción de la vivienda y espacios públicos, relaciones vecinales y uso de los espacios.

Ambas técnicas complementadas entre sí, permiten construir argumentos robustos que logran conocer en profundidad las percepciones de los usuarios, como sus prácticas y su relación con el espacio físico. Además, estas técnicas fueron aplicadas mediante un corte temporal que va desde el 1 de agosto de 2016 al 30 de octubre de 2016, siendo una investigación de carácter transversal. No obstante, en cuanto al mantenimiento 
físico del barrio, se realizó un nuevo proceso de observación durante junio y julio del año 2018.

La muestra escogida para la entrevista pasó por el siguiente proceso de selección:

Usuarios que sean el beneficiario del subsidio habitacional, dado que aseguraba que hayan participado en las distintas aristas que incorpora la actual política habitacional, la que se concentra en los Jefes de Hogares y no en todo el grupo familiar. En este sentido, en cuanto a los jefes de hogares que conformaban el comité de vivienda, eran un su mayoría mujeres, por lo cual la muestra buscó mantener dichos criterios.

Se decidió partir por entrevistar a la presidenta del comité del campamento que lideró el proceso de traslado hacia la Villa General Bernales y una vez contactada la dirigente, posteriormente comenzar con entrevistados que hayan participado a juicio de la dirigente, activamente en el proceso de consecución de la vivienda. Así, fue posible entrevistar a 8 jefes de hogares (Tabla 1) todos provenientes del campamento Peñoncito.

\section{Tabla 1}

\section{Muestra del estudio}

\begin{tabular}{|c|c|c|}
\hline Contacto con las fuentes & Fecha inicio & $\begin{array}{l}\text { Tiempo que habitó en el } \\
\text { campamento. }\end{array}$ \\
\hline $\begin{array}{l}\text { Entrevista a dirigente del comité de vivienda (informante clave). } \\
\text { Mujer } 49 \text { años. }\end{array}$ & 9 de septiembre de 2016 & 15 años \\
\hline Entrevista a pobladora número 2. Mujer, 53 años. & 9 de septiembre de 2016 & 13 años \\
\hline Entrevista a pobladora número 3 . Mujer, 33 años. & 28 de septiembre de 2016 & 10 años \\
\hline Entrevista a pobladora número 4. Mujer, 45 años & 5 de octubre de 2016 & 15 años \\
\hline Entrevista a poblador número 5 . Hombre, 48 años & 5 de octubre de 2016 & 12 años. \\
\hline Entrevista a pobladora número 6 . Mujer, 29 años. & 12 octubre de 2016 & 8 años. \\
\hline Entrevista a poblador número 7. Hombre, 54 años. & 15 de octubre de 2016 & 12 años \\
\hline Entrevista a pobladora número 8. Mujer, 44 años. & 25 de octubre de 2016 & 9 años \\
\hline Observaciones participantes (10 visitas) & $\begin{array}{c}1 \text { de agosto al } 30 \text { octubre de } \\
2016 \text { y } 1 \text { junio al } 30 \text { de julio de } 2018\end{array}$ & \\
\hline
\end{tabular}

Elaboración propia

La información construida fue analizada mediante la técnica de análisis de contenido la cual se define como análisis metodológicamente controlado de textos al interior de sus contextos de comunicación, siguiendo reglas analíticas de contenido y modelos paso a paso, sin cuantificación. "Tratado como técnica aplicable a la reelaboración y reducción de datos, que se beneficia del enfoque emergente propio de la investigación cualitativa" (Cáceres, 2003, p.57).

\section{Resultados}

Los resultados construidos a partir del trabajo de campo se abordan mediante tres dimensiones. Una primera variable hace relación con los niveles de satisfacción respecto a la solución habitacional recibida. Una segunda dimensión, estudia los niveles de apropiación barrial de los vecinos frente al barrio $y$, por último, la tercera dimensión abarca un análisis material del barrio y su mantención física en el tiempo. 


\section{Satisfacción Residencial: Condiciones De Vida Digna}

Al abordar la satisfacción de los entrevistados respecto a la solución habitacional recibida, todos plantean sentirse conformes con su actual vivienda, y consideran que existe un mejoramiento importante frente a las condiciones materiales en las cuales habitaban anteriormente, dado que pasaron de vivir en una vivienda de material ligero a viviendas construidas con albañilería y que cumplen con los diferentes requerimientos normativos respecto a estructura, resistencia y aislación.

La magnitud del cambio material y cómo esto permea la satisfacción de los entrevistados, se gráfica de mejor forma, en función de las problemáticas que debían sufrir en el campamento para, por ejemplo, períodos de lluvia o invierno, ya que, por un lado, debido a las bajas temperaturas respecto a las cuales las viviendas no contaban con el sistema constructivo adecuado para dar resistencia, las familias se veían expuestas a dormir con temperaturas muy similares a lo que era la intemperie, obligándolos además a recurrir a prácticas de calefacción que pudiesen ser peligrosas para el grupo familiar y para la vivienda misma, como es el uso de fuego. Sumado a esto, en épocas de lluvia, muchas de estas casas no lograban mantener el interior de la vivienda aislado del agua, ya que contaban con diferentes filtraciones, tanto en muro como techumbres, que hacían de la vivienda un lugar húmedo y afecto a diferentes enfermedades.

Así, una entrevistada nos comenta su percepción respecto al cambio experimentado:

Fue cambiar mucho, imagínate de pasar de vivir en campamento, vivir en el barro, pasar todos mojados a cambiar a una calle donde a lo mejor sí te mojay, pero no te embarray, o si pasay frío afuera, pero no adentro. Allá no po, allá pasaba frío adentro y afuera de la casa ha sido un mejoramiento en el bienestar de mis hijos po $y$ que claramente no pasaba en un campamento. Ponte tú, acá tienen su propia pieza, los dos hombres en una pieza y la mujer en otra. Allá no po, todos en una mediagua de poco más de $3 \times 6$ todos juntos, acá no po, cada uno tiene su pieza y su espacio. (Mujer, 33 años, 10 años en el campamento)
Por otro lado, se siente plena satisfacción por el mejoramiento en cuanto a la dotación de servicios y los espacios públicos a los cuales tienen acceso las familias, como se ejemplifica en la siguiente cita:

Tenemos agua, ya no tenemos que estar pidiéndole a la muni, ¿cachai? Ya no tenemos que estar llamando y rogando que traigan agua. No porque ahora tu pagay el agua ahora, teni las plazas que los niños pueden estar todos columpiándose ahora. (Hombre, 54 años, 12 años en el campamento)

Otros de las factores relevantes y más reiterativos a lo largo de las entrevistas, tiene relación en cuanto a la satisfacción de contar con un bien material propio y que por sobre todo pueda ser heredable para los hijos. Por lo cual, el factor de la propiedad privada es otro componente más que incidiría en el deseo de mantener de buena forma este bien personal y el entorno que lo rodea. Uno de los entrevistados lo grafica del siguiente modo:

Ha sido lindo tener algo propio, algo tuyo que le vas a poder dejar a tus hijos, que ya sabes que si a ti te pasa algo ellos no van a quedar en la calle, como nos pasaba con el campamento, que uno sabía que no le iba a dejar nada a tu familia ni a nadie. (Hombre, 48 años, 12 años en el campamento)

No obstante, si bien los niveles de satisfacción con la solución habitacional son altos, si es posible identificar durante las entrevistas elementos que parecieran ser considerados como negativos en cuanto al proceso de mudanza que estas personas se han visto afectos.

Como primer punto se habla respecto al tema de la espacialidad, dado que todos los entrevistados provienen de un asentamiento informal, donde no existía límite en cuanto a las dimensiones habitacionales, a diferencia del barrio donde deben adaptarse a estándares previamente definidos y que en general son de menor tamaño que la anterior.

Esta situación trae como efecto dos acciones que son reiteradas. Por un lado, en cuanto al aspecto físico, se da en variadas viviendas una serie de ampliaciones informales que alteran la estructura original del barrio. $Y$, por otro lado, está el hecho de que la proximidad entre 
viviendas aumenta los niveles de convivencia entre vecinos, lo cual ha tenido como problemática temas relativos al ruido que se realiza al interior de las viviendas y que tiene desconforme a un grupo de familias en cuanto sus nuevos vecinos, lo que habla de un cierto malestar en cuanto a la convivencia en el barrio.

Esto es aquí no más, en este ladito no más que pasa esto, pero yo decía icaramba! Las mamás tan desconsideradas. Hasta el momento no se les ha puesto ni un reclamo a la gente y no les han dicho nada o no se si no les han dicho nada, a lo mejor sí y les importa un carajo si la vecina le molestó la música o se siente mal, o le duele la cabeza o no le gusta la música que escucho, ayer parecían disco rayado, reggaetón, cumbia, rancheras, al final era un revoltijo de música que mis oídos no aguantaban. (Mujer, 44 años, 15 años en el campamento)

Frente a esta problemática es importante destacar que los vecinos de la Villa no son los mismos que en el campamento, ya sea porque el ordenamiento de las familias es nuevo, o porque se integran también familias de otros sectores a vivir en el conjunto habitacional. Además, las condiciones de espacialidad previas hacen difícil la existencia de problemáticas por ruidos molestos.

Por último, otra problemática que comentaron algunos de los entrevistados, tiene que ver con la carga económica que significa ser propietario de una vivienda, en la cual, a diferencia del campamento, se debe contar con un ingreso mensual fijo que permita costear los diferentes gastos que conlleva una vivienda, tales como el pago de cuentas o la mantención de ésta. Esto genera, por un lado, la incapacidad económica de mantener en buen estado la vivienda, lo que crea un deterioro del barrio; $y$, por otro lado, se produce una carga emocional para el o los jefes de hogar, que incluso podría desencadenar en buscar dejar la vivienda y volver a un asentamiento irregular.

En el campamento no teníay, como es que te dijera, esa espera que va a llegar el fin de mes y tengo que pagar la luz o que me van a cortar la luz si es que no pago. Hay personas que trabajan para puro pagar los suministros, nada más. Y los que no tienen trabajo van a seguir siempre encalillándose, porque ponte tú pueden pagar este mes, me van a dar la luz y el agua, pero el otro mes me la van a volver a cortar porque no voy a poder pagar, si no tení algo estable. (Mujer, 53 años, 13 años en el campamento)

De todas formas, es posible concluir que en términos generales las percepciones de satisfacción que construyen los entrevistados en cuanto al barrio y solución habitacional recibida es positiva y valorada. De este modo $y$, tomando en consideración los antecedentes teóricos, se aprecia que está satisfacción influirá en que las prácticas al interior del barrio vayan en relación con el cuidado de éste, a partir de la mencionada relación entre los grupos humanos, su subjetividad individual y el espacio físico en el que se desenvuelven.

\section{Apropiación barrial: La vivienda como una Lucha}

En cuanto a la apropiación barrial, y el grado de identificación subjetiva que los vecinos tienen por su barrio, es coincidente con los niveles de satisfacción, ya que, en general, todos los entrevistados comentaron sentirse orgullosos de habitar en la Villa General Bernales.

Lo anterior, se encuentra condicionado, en particular, porque la mayoría de los entrevistados considera que debieron pasar por un proceso de lucha colectiva, para poder concretar su solución habitacional, la cual demoró más de 10 años. En este sentido, la dirigente del comité habitación realiza el siguiente comentario:

Es una lucha que hicimos con el Orlando de tener nuestra casa y lo que queríamos nosotros para nuestros hijos. Un alivio que ellos van a tener para bañarse, la luz, el agua, una de esta que no van a pasar frío. (Mujer, 49 años, 15 años en el campamento)

En este sentido, es posible observar que el esfuerzo adjudicado a la concreción de la solución habitacional sirve como base para tener un alto grado de apreció por la solución conseguida, como comenta una de las vecinas entrevistas:

Sí, porque yo decía tanto luchar, tanto sufrir, tanto mamarte tanto frío, tantas cosas. $Y$ que después te digan "ya, hoy día es". Tení que, como te dijera, analizarlo, como que harto costaron los sacrificios que tú tuviste que hacer para lograr lo 
que tenemos. (Mujer, 53 años, 13 años en el campamento)

Así, este nivel de orgullo y aprecio por la solución obtenida, repercute directamente en diferentes prácticas que se dan al interior del barrio, que hablan de un cuidado por el mismo, las cuales incluso, no necesariamente se llevaban a cabo en el campamento Peñoncito. Uno de los entrevistados cuenta su percepción respecto a las prácticas de los vecinos al interior del conjunto habitacional:

Ahora son más reservados que allá abajo. Claro, allá abajo no, abajo (en el campamento) se compartía no más, ahora se comparte dentro del rancho no más y queda todo ahí. Ya nadie anda de allá pa acá como antes, uno que otro no más y tampoco curado, yo cuando vengo curado, abro mi puerta y a dormir. (Hombre, 48 años, 12 años en el campamento)

Esta idea también es compartida por el resto de los entrevistados como se grafica en la siguiente cita:

Más encima que la gente igual ha cambiado acá, tu no vay pa afuera y vei a gente tomando, nada de eso como allá que se amanecían tomando, fumando y bailando, acá no po que tienen hasta cierta hora no más con la música y chao pescao. (Mujer, 29 años, 8 años en el campamento)

Por otro lado, y quizás una de las implicancias que se podría considerar dentro de las más relevantes tiene que ver con una percepción respecto a la responsabilidad de tener que cumplir con la mantención de la vivienda y sostén familiar, desde una forma autónoma, y no asistencial, como pareciera ser que se daba en el campamento, lo cual ha traído cambios, como, por ejemplo, en las prácticas laborales de los vecinos. La dirigente del conjunto nos comenta la siguiente apreciación:

El mayor cambio es que la gente se hizo más responsable, en el campamento no eran tan responsables como acá. Porque en el campamento tu no pagay agua, luz, no estay ni ahí, si querí trabajay, si querí no trabajay. Acá no po, acá tienen que trabajar. Acá no te van a venir a dejar mercadería ahora, no te van a regalar las cosas pa los cabros chicos, tení que trabajar pa eso, tení que apoyar pa eso. Ahora no saben si va a llegar el tío y te va a dar el regalo, no sabemos si este año va a trabajar con nosotros, así que todos son más responsables. (Mujer, 49 años, 15 años en el campamento)

Si bien, en base a los puntos anteriormente mencionados, se podría considerar, en general, que las percepciones son más bien positivas en cuanto al conjunto habitacional, existe un punto en que todos los entrevistados comentaron sentirse nostálgicos a como se daba en el campamento, el cual tiene que ver con las relaciones sociales que se dan al interior del barrio.

Elemento que tienen implicancias directas en las percepciones subjetivas de los vecinos y con el vínculo emocional que se puede construir con el espacio físico, tal como se muestra en los antecedentes conceptuales.

Los entrevistados concuerdan en que ha existido una ruptura del tejido social, ya sea, tanto en el uso del espacio público, como en las relaciones entre los propios vecinos. Asegurando que, en la actualidad, las familias se han recluido a realizar un mayor uso del espacio privado, y que han quedado atrás componentes de solidaridad que eran muy latentes en el campamento:

Allá todos nos conocíamos yapo, era diferente, acá hay muchos que los conocí, pero no tení idea en verdadpo. Allá éramos como una familia gigante igual aquí igual los veí y todo, pero no es lo mismo. Porque allá los veíay a todos así apatonados ahí, aquí nopo, están todos dispersos. Ponte los que vivían al lado de nosotros allá, acá están todos en la avenida. (Mujer, 33 años, 10 años en el campamento)

Incluso una de las entrevistadas comenta que no solo existe una disposición a recluirse en la vivienda, sino que además existe actitudes de denostación entre vecinos, a partir de, por ejemplo, ciertas diferencias económicas como se presenta en la siguiente cita:

Hubo mucha gente que confundió tener su casa a levantarse de raja que ellos no eran parte de vivir en un campamento ¿cachay? Hay mucha gente que ahora te mira por encima del hombro, que eso antes no lo hacían éramos todos iguales po, pero como te digo, hubo ese cambio cuando nos vinimos para acá, ya no éramos iguales. Algunos 
como que tenían más que los demás siendo que, yo creo que está bien, te viniste a una casa, pero no creo que te hayan cambiado tu personalidad. Yo sigo siendo la misma, a mí me da lo mismo, soy la misma que estaba en el campamento, pero hay personas que no entienden eso. (Mujer, 53 años, 13 años en el campamento)

Sin embargo, es posible considerar que existe un nivel de apropiación por el espacio, lo cual va quedan marcado por sobre todo a partir de la idea de sentir que se llevó un proceso de lucha y de esfuerzo, que culminó de forma exitosa. Elemento que está influenciado a partir del hecho de pasar por un proceso donde los beneficiarios sienten haber jugado un rol, producto que al igual que con los niveles de satisfacción, debiese dirigir a que las familias y habitantes del barrio, estén propensos a realizar acciones que vayan en pos de la mantención y mejoramiento de éste.

\section{Villa General Bernales: El barrio como oportunidad}

Al recorrer las calles y pasajes de la Villa General Bernales, es posible evidenciar distintos contrapuntos respecto al estado y uso de este conjunto habitacional. En este sentido, se plantea un análisis que cuenta con dos partes, uno orientado al espacio privado de los vecinos, es decir, sus viviendas y, por otro lado, uno en cuanto a los espacios públicos o comunitarios.

Respecto al análisis en cuanto al estado físico de las viviendas de la Villa General Bernales, se considera que no es sencillo generalizar respecto al estado y mantención de éstas. Si bien es importante reconocer que, realizando un recorrido rápido por el barrio, es posible observar como un grupo no menor de familias (30\% aprox.) ha realizado modificaciones importantes a sus viviendas, mediante ampliaciones y modificaciones estructurales.

Lo anterior y, según lo rescatado en las entrevistas, responde a la necesidad de contar con mayor espacio para el grupo familiar ya sea por problemáticas de hacinamiento, como por condiciones labores, como ocurre con ciertas viviendas que se han modificado para contar con locales comerciales. Incluso existirían vecinos que solo contaban con el deseo de tener más espacio, elemento que estaría fuertemente marcado por los espacios que contaban previo a su llegada al barrio.
Es importante reconocer que las ampliaciones no son necesariamente una variable que genere un deterioro del estado de las viviendas. No obstante, en la mayoría de los casos -según lo observado y conversado con la dirigente del conjunto- son ampliaciones de carácter irregular que no cuentan con permiso municipal $y$, por ende, no cumplen con normas mínimas de constructibilidad. Incluso es posible apreciar viviendas modificadas con material ligero.

Además, en cuanto a la imagen física del barrio, se produce que a diferencia del momento de la entrega de éste: hoy existe una mayor heterogeneidad visual respecto a las viviendas, la cual produce a juicio del observador un mayor nivel de desorden y armonía.

En esta misma línea, otro elemento diferenciador y que resalta al momento de recorrer el barrio tiene que ver con la instalación de rejas. Dado que el diseño original del conjunto no considera la instalación de rejas, cada familia debía responsabilizarse por buscar, escoger e instalar sus propios cierres. Esto genera que, a la fecha, exista una variedad total en los cierres de las viviendas, ya sea en cuanto materialidad, tamaño o color.

Quizás, una de las posibles problemáticas que podría contener esta situación, hace relación con que por lo menos en términos visuales, es fácil identificar diferencias económicas entre las viviendas, ya que incluso existen familias que, a la fecha, no cuentan con cierres, o tienen cierres precarios, ya sea con latas o mallas (Figura 2), a diferencia de viviendas que cuentan con rejas de madera (Figura 1) u otro material. Este hecho podría facilitar que se reproduzcan al interior del barrio, prácticas discriminatorias frente a las viviendas con peores cierres, junto con que en términos visuales, le da una imagen al barrio de mayor precariedad.

Si bien es posible mencionar que en términos visuales las viviendas del conjunto se mantienen en general en buen estado, los elementos mencionados pueden ser un riesgo para el posible deterioro físico del barrio y, por ende, en un largo plazo, podría ser dañino para las prácticas y percepciones del barrio. 


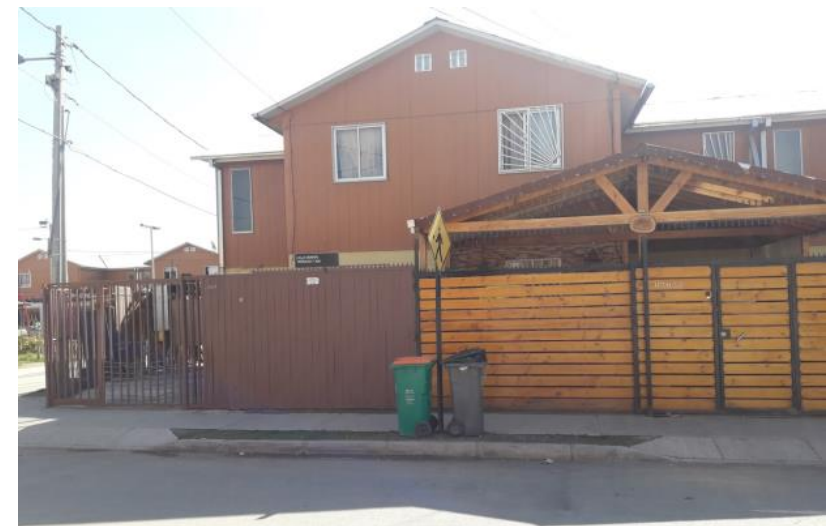

Figura 1. Cierre de madera, Villa General Bernales.

Fuente: elaboración propia.

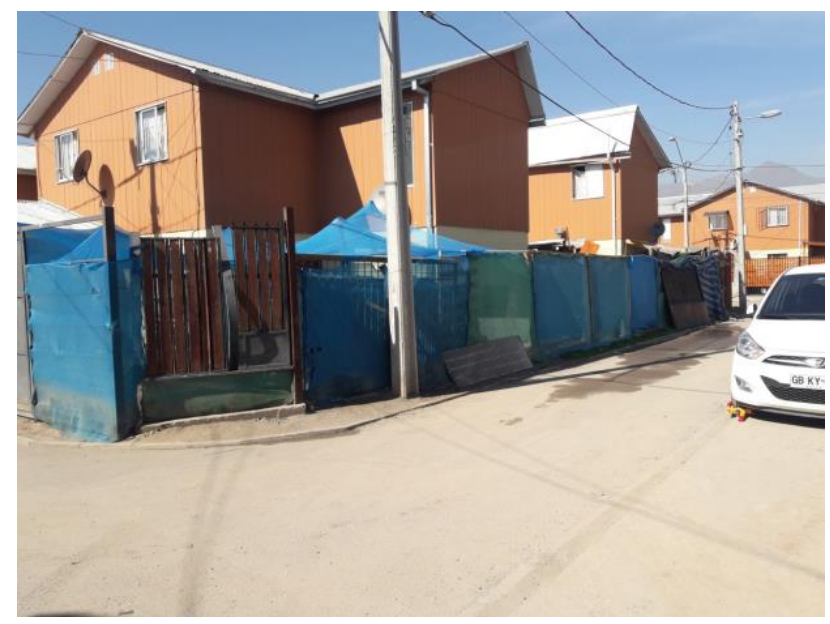

Figura 2. Cierre de malla, Villa General Bernales

Fuente: elaboración propia.

En cuanto a los espacios públicos, es importante destacar que más allá de las calles y aceras de la Villa General Bernales, el conjunto cuenta con diferentes equipamientos comunitarios: 3 áreas verdes, una sede social y una multicancha.

En términos generales, se debe mencionar que en términos visual se observa que no cuenta con grandes deterioros físicos. Por ejemplo, al realizar un recorrido por el lugar, es posible observar áreas verdes bien mantenidas (incluso en diferentes visitas, se apreciaron vecinos del sector regando las distintas áreas verdes). Por otra parte, siempre se vio a niños de todas las edades haciendo uso de los juegos infantiles, frente a lo cual se apreció la mantención de los mismos, salvo pequeños detalles.

Sin embargo, existen algunos elementos a tener en consideración y que podrían ir en favor del deterioro de las áreas verdes del conjunto, ya que, por un lado, fue posible reconocer la presencia de basura en ciertos sectores, e incluso ver a personas de la comunidad botando diferentes elementos a la calle o al interior de las áreas verdes. No obstante, se consideraron como hechos que no denotaban mayor envergadura.

Por otro lado, fue posible observar la mala utilización de las áreas verdes en cuanto al uso diseñado, ya que ciertos sectores son utilizados como estacionamientos, lo cual claramente va generando un deterioro de elementos como el césped y reduce el área de utilización de dichos espacios.

Respecto a la sede social, es posible apreciar que este equipamiento ha podido mantenerse de buena forma con el paso del tiempo, destacando la mantención en la fachada y espacios interiores. Además, durante la observación fue posible apreciar que la sede se utiliza para diferentes acciones comunitarias, como son las asambleas, celebración de actividades, talleres formativos y otras actividades.

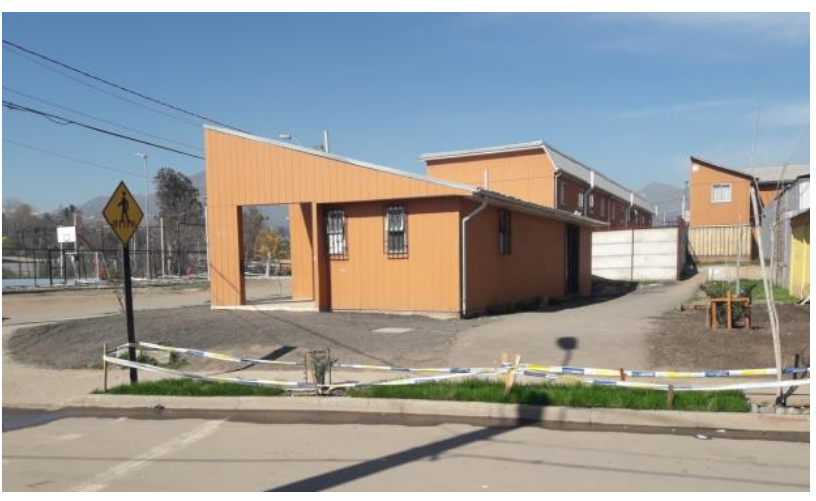

Figura 3. Sede Social, Villa General Bernales.

Fuente: elaboración propia.

Por último, cabe destacar que, desde el primer proceso de observación realizado durante el año 2016, a una segunda revisión durante el año 2018, la comunidad fue capaz de gestionar en conjunto, el aporte de privados y del municipio de la comuna, en dos nuevos espacios públicos, que son la construcción de una multi-cancha y de una nueva área verde. Ambos espacios al momento 
de las últimas observaciones eran ampliamente utilizados por la comunidad, y dado el poco tiempo que ha trascurrido desde que fueron ejecutados, se mantienen en perfectas condiciones.

Así, es posible señalar según lo observado que, en términos generales, la Villa General Bernales ha sido capaz de mantenerse con el paso de los años, siendo un espacio que sigue cumpliendo principalmente con sus condiciones originales y que tanto complacieron a sus usuarios. Si bien es importante destacar que como en todo proceso social y físico, existen elementos posibles de mejorar o de tener en consideración.

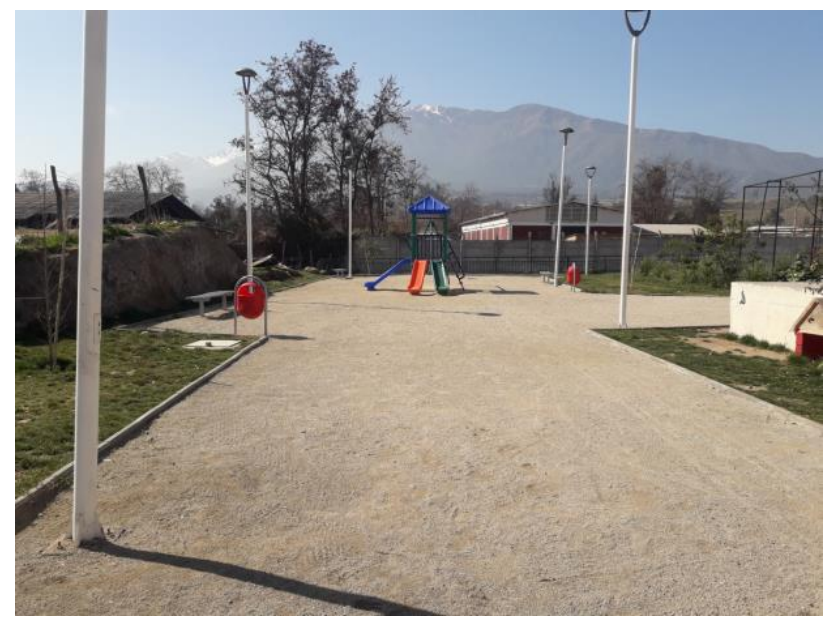

Figura 4. Nueva área verde, Villa General Bernales.

Fuente: elaboración propia.

\section{Conclusiones}

Este artículo buscó ser un aporte en profundizar el estudio de la relación espacio - sociedad, y cómo el vínculo entre estas dimensiones puede ser un aporte en la construcción y diseño de las ciudades.

Así, mediante el presente estudio de caso, se buscó observar cómo son las percepciones de satisfacción y apropiación barrial de usuarios de las actuales políticas habitacionales, junto con observar el estado físico del barrio en el que habitan.
En este sentido, se concluye que, para el caso estudiado, las percepciones en cuanto a la satisfacción por la vivienda y barrio recibido son positivas, como a su vez, existe dentro de los entrevistados un alto grado de pertenencia con el territorio. Además, se concluye que el espacio físico, si bien ha ido teniendo modificaciones con los años, éste no se ha visto deteriorado sustancialmente en términos de materialidad, a diferencia de otros casos de estudio de anteriores políticas habitacionales.

Por otra parte, se sugiere que tanto las percepciones de satisfacción como la apropiación del barrio, tienen relación con el proceso previo a la entrega de las viviendas, el cual se encuentra en un contexto en donde las familias vivían en condiciones habitacionales precarias y debieron generar mecanismos de organización comunitaria que les permitieran salir adelante. No obstante, es probable que también incidieron las condiciones de la nueva política habitacional, entregando la posibilidad de embarcarse dentro de un proceso de orden colectivo, donde fue posible que influyesen en el diseño del conjunto, y fueran capacitados en diferentes temáticas de cuidado y administración del espacio.

A su vez, es muy probable que las percepciones positivas de satisfacción y apropiación influyan directamente en la mantención, cuidado y mejoramiento del barrio, a diferencia también de los casos anteriormente mencionados. Si bien son lineamientos que se deben seguir profundizando, es predecible sostener que si la política habitacional sigue incorporando dentro de sus lineamientos, un mejor estándar de las viviendas junto con mecanismos que promuevan la participación ciudadana permitirá promover el desarrollo de barrios que cuenten con habitantes con percepciones positivas y menos deteriorados físicamente en el tiempo [B] 


\section{Referencias}

Annunziata, R. (2013). Una propuesta de clasificación de los dispositivos participativos en Argentina. PostData, 18(2), 247-280.

Cáceres, P. (2003). Análisis cualitativo de contenido: Una alternativa metodológica alcanzablePsicoperspectivas, (2), 53-82.

Castillo Cubillos, M. (2017). El papel de la participación ciudadana en las políticas públicas, bajo el actual escenario de la gobernanza: reflexiones teóricas. Revista CS, 123), 157-180. https://doi.org/10.18046/recs.i23.2281

Decreto Supremo 174. Diario Oficial de la República de Chile, Santiago, Chile, 30 de septiembre de 2005.

Decreto Supremo 49. Diario Oficial de la República de Chile, Santiago, Chile, 13 de septiembre de 2011.

Hidalgo, R., Urbina, P., Alvarado, V. y Paulsen, A. (2017). Desplazados y ¿olvidados?: contradicciones respecto de la satisfacción residencial en Bajos de Mena, Puente Alto, Santiago de Chile. INVI, 30(91), 53-65. https://doi.org/10.4067/s0718-83582017000100085
Kuri, E. (2013). Representaciones y significados en la relación espacio-sociedad: una reflexión teórica. Sociológica, 28(78), 69-98.

Marín, A., Link, F. y Valenzuela, F. (2017). Arriendo en propiedad: arraigo y vulnerabilidad residencial en el barrio Puerto de Valparaíso. INVI, 32(90), 127-157. http://dx.doi.org/10.4067/S0718$\underline{83582017000200127}$

Sabatini, F., Cáceres, G. y Cerda, J. (2001). Segregación residencial en las principales ciudades chilenas: tendencias de las tres últimas décadas y posibles cursos de acción. EURE 27(82), 21-42. https://doi.org/10.4067/s0250-71612001008200002

Rodríguez, A. y Sugranyes, A. (2004). El problema de vivienda de los "con techo". EURE, 30(91), 53-65. https://doi.org/10.4067/s0250-71612004009100004

Vidal, T. y Pol, M. (2005). La apropiación del espacio: una propuesta teórica para comprender la vinculación entre las personas y los lugares. Anuario de Psicología, 36(3), 281-297. 